\title{
Unraveling Yields Inefficient Matchings: Evidence from Post-Season College Football Bowls
}

\section{Citation}

Fréchette, Guillaume, Alvin E. Roth, and M. Utku Unver. 2007. Unraveling Yields Inefficient Matchings: Evidence from Post-Season College Football Bowls 38, no. 4: 967-982.

\section{Published Version}

http://www3.interscience.wiley.com/journal/121441288/abstract

\section{Permanent link}

http://nrs.harvard.edu/urn-3:HUL.InstRepos:2570385

\section{Terms of Use}

This article was downloaded from Harvard University's DASH repository, and is made available under the terms and conditions applicable to Other Posted Material, as set forth at http:// nrs.harvard.edu/urn-3:HUL.InstRepos:dash.current.terms-of-use\#LAA

\section{Share Your Story}

The Harvard community has made this article openly available.

Please share how this access benefits you. Submit a story.

Accessibility 


\title{
Unraveling yields inefficient matchings: evidence from post-season college football bowls
}

\author{
Guillaume R. Fréchette* \\ Alvin E. Roth** \\ and
}

M. Utku Ünver***

Many markets have "unraveled" and experienced inefficient, early, dispersed transactions, and subsequently developed institutions to delay transaction timing. It has previously proved difficult, however, to measure and identify the resulting efficiency gains. Prior to 1992, college football teams were matched for post-season play up to several weeks before the end of the regular season. Since 1992, the market has reorganized to postpone this matching. We show that the matching of teams affects efficiency as measured by the resulting television viewership, and that the reorganization promoted more efficient matching, chiefly as a result of the increased ability of later matching to produce "championship" games.

\section{Introduction}

- Many market institutions have evolved to coordinate the timing of transactions, and to prevent them from taking place too early, or at uncoordinated times. Some prominent examples of markets in which early transactions have been a problem are markets for new physicians, for new law graduates (particularly those who seek federal appellate clerkships), and for undergraduate college admissions. ${ }^{1}$ At some points in the history of each of these markets, transactions have

\footnotetext{
*New York University; frechette @ nyu.edu.

**Harvard University; aroth@hbs.edu.

*** University of Pittsburgh; uunver@pitt.edu.

We thank Jo LaVerde of Nielsen Media Research for providing us Nielsen's rating data and Kenneth Massey for directing us to information about college football rankings. We have had helpful conversations on this subject with Dave DeJong and Muriel Niederle. We also thank the editor and two referees for helpful comments. Fréchette gratefully acknowledges the support of the NSF via grant SES-0519045 as well as support from the Center for Experimental Social Science and the C.V. Starr Center. Roth gratefully acknowledges the support of the NSF via grant SES-0616470. Unver gratefully acknowledges the support of the NSF via grant SES-0616689.

${ }^{1}$ See, e.g., Roth (1984, 1991), Avery, Jolls, Posner, and Roth (2001, 2007), and Avery, Fairbanks, and Zeckhauser (2003). Roth and Xing (1994) discuss many other examples of such markets, including many centralized market mechanisms, where as Niederle and Roth (2006) consider informal "market cultures" that influence transaction times.
} 
unraveled, that is, have tended to be finalized earlier and earlier in advance of when the transacted relationship would begin (i.e., increasingly before graduation from medical school, law school, or high school).

There are good theoretical reasons for believing that early transactions may be (at least ex post) inefficient, if information important for determining match quality evolves over time. In such markets, transactions arranged before critical information (such as grades) becomes available will not be able to achieve matchings as efficient as could be made after the necessary information was available. ${ }^{2}$

Except for evidence from laboratory experiments, however, there has so far been no direct evidence confirming that unraveling results in inefficiently early matches (i.e., confirming that unraveling occurs even when it is inefficient). ${ }^{3}$ This is largely because of the difficulty of measuring production, and how it varies with match quality, in medicine, law, education, and so forth. For instance, there has been no way to measure the effect on the quality of American health care, of changes in the times at which resident physicians are hired by hospitals, or even on a narrower measure of efficiency such as medical costs, physician wages, and hospital revenues. ${ }^{4}$ The same can be said for the production of justice by judges and their clerks, the quality of education produced by colleges and undergraduates, among other things.

Niederle and Roth $(2003 \mathrm{~b}, 2004,2005)$ and Niederle, Proctor, and Roth (2006) took advantage of a disruption in the market for gastroenterologists to observe that periods in which transactions were made relatively early were marked by a decrease in the scope of the market. During periods in which contracts were signed relatively late, the market was more national in scope than when contracts were signed early. During periods in which contracts have been signed early, gastroenterologists were more likely to pursue their careers in the same local market in which they were internal medicine residents. So Niederle and Roth showed that a change in the timing of the market led to a change in the outcomes it produced. Although a breakdown of the national market into local markets is likely to deprive the market of its ability to find the most efficient matches, however, Niederle and Roth's data do not show this directly, neither in the narrow sense of medical revenues nor in the wider sense of reduced gastroenterological disease.

We consider the market for post-season college football games, called "bowls." In the early 1990 s, the determination of which teams would play each other in which bowls was often made when several games still remained to be played in the regular fall season (cf Roth and Xing, 1994). This meant that the teams with the best end-of-regular-season records might not play one another, because at the time the matchings were determined it was not yet known which teams these would be. Over the last decade this market has undergone a number of reorganizations that have delayed this matching decision until the end of the fall regular season.

Using Nielsen rating data on television viewership and the AP Sports Writers' poll of team rankings, we will show that, by matching later, the chance of matching the best teams has increased, and the result is an increase in television viewership. Television viewership is related to both the broad measure of efficiency in terms of how much entertainment is provided by the games and the narrow measure in terms of how much revenue accrues to the bowls and football conferences and teams associated with the organization of late season matching. Because there has been variation over the years in the rankings of matched teams, we will also be able to infer

${ }^{2}$ For theoretical models expanding on this point, see, e.g., Roth and Xing (1994), Li and Rosen (1998), Li and Suen (2000, 2004), and Suen (2000). For theoretical models on other issues regarding unraveling in centralized markets, see, e.g., Sönmez (1999), Kesten (2005), and Kojima (2006).

${ }^{3}$ For computation and laboratory experiments in which early transactions occur despite being inefficient, see Kagel and Roth (2000), Ünver (2001, 2005), McKinney, Niederle, and Roth (2005), Haruvy, Roth, and Ünver (2006), and Niederle and Roth (2006). Although experiments are well suited to showing that unraveling can occur even when it is inefficient, they do not demonstrate that the unraveling observed in the particular natural markets of interest is also necessarily inefficient. Nor do they give us any way to assess the magnitude of the inefficiency observed in natural markets.

${ }^{4}$ For medical fellowships, positions that involve a substantial training component, wages appear to be influenced far more by other factors (Niederle and Roth, 2003a). 
how different components of the post-season matches contribute to total television viewership of the bowl games. Efficient matching, it turns out, is especially sensitive to the presence of a "championship" game matching the two teams that are highest ranked at the end of the regular season.

This article provides, as far as we know, the first direct evidence and measurement of the inefficiency due to early transaction times in a naturally occurring market. When the bowl games have been matched later, the quality of the teams matched to bowls has improved, the likelihood of a championship game has increased, and the total viewership of all the bowls in the late-matching consortia has increased.

\section{Short history of college bowls and unraveling}

- Throughout the fall of each year, college football teams play each other every weekend, and are ranked the following week in widely publicized polls of coaches and sports writers. ${ }^{5}$ After the end of the regular season, selected teams meet each other in post-season games, called bowls, which are played in late December and early January.

The bowls are independent businesses, each of which controls a stadium and makes contracts with corporate sponsors. Prior to 1992, most bowls had long-term contracts with football conferences. The Rose Bowl was a "closed" bowl, in which the champion of the Big Ten and Pacific Ten football conferences played each year. ${ }^{6}$ The Fiesta Bowl was an "open" bowl, which each year needed to find two teams to play against each other. The other major bowls were "semi-closed," with a contract to host the champion of a particular conference and needing to find a suitable opposing team. ${ }^{7}$

The National Collegiate Athletic Association (NCAA) tried for years to prevent unraveling of the dates at which bowls and teams finalized agreements about which teams would play in which bowls. However, it gave up in failure following the 1990-1991 football season, in which early matching (once again) led to poorly matched teams. ${ }^{8}$ There was growing concern that interest in the bowl games was waning because poor matches led to a lack of consensus on a "national champion" that would result if there were a bowl game in which the number 1 and 2 ranked teams played one another.

To summarize the situation prior to 1992, several institutional features prevented good bowl matches. The Rose Bowl was not involved in unraveling, as it had a long-term contract that brought in two conference champions. Because it dealt with only two conferences, however, these conference champions might not be closely ranked to one another (and would very seldom be

\footnotetext{
${ }^{5}$ The Sports Writers' Poll is sponsored by the Associated Press (AP). The (Division I-A) Coaches' Poll is today sponsored by USA Today/ESPN, and was sponsored from 1950 to 1990 by United Press International (UPI), and from 1991 to 1996 by USA Today/CNN.

${ }^{6}$ The latter was previously called the Pacific Eight and Pacific Coast conference. The name changes reflected the changing team membership.

${ }^{7}$ The champion of the Big Eight Conference (now enlarged to the Big Twelve) played in the Orange Bowl, the Southeastern Conference champion in the Sugar Bowl, Southwest in the Cotton Bowl, and the Atlantic Coast Conference (ACC) champion in the Citrus Bowl (with some escape clauses in case the ACC champion was ranked highly enough in the UPI Coaches' Poll to be a contender for the unofficial post-season "national championship" ranking in the AP Sports Writers' and UPI Coaches' polls following the bowl games). Not all teams belong to conferences; the independent teams included traditional football powers Notre Dame, Penn State (joined Big Ten in 1990), and Miami (joined Big East in 1991, moved to ACC in 2004).

${ }^{8}$ Through the 1990-1991 season, the NCAA specified a date (colloquially called "Pick-Em Day") before which bowls and teams were forbidden to sign agreements. However, this agreement was widely and publicly flouted, and the NCAA abandoned its attempt to control this market after the 1990-1991 season, in which, with four games still to go in the regular season, Notre Dame agreed to meet the still-undetermined Big Eight champion in the Orange Bowl, Virginia agreed to play in the Sugar Bowl against the still-undetermined Southeastern Conference champion, and Miami agreed to play in the Cotton Bowl against the still to be determined Southwest conference champion. At the time of the agreement, Notre Dame was the number 1 ranked team in the nation, but between the agreement and the end of the season they lost a game and fell to number 5. Virginia lost two games, and fell entirely out of the top 25 AP rankings, and to 23 in the UPI Poll. (See Roth and Xing, 1994, and, for accounts of prior years, see, e.g., Barnhart, 1989; Harig, 1990.)
} 
the two highest ranked teams nationally). The other major bowls dealt with a substantial pool of conferences and teams, but because of unraveling of bids for their open slots, these were filled without knowing the end-of-season rankings of the teams invited to play. And because many bowls had one position reserved for a particular conference champion, this also limited the matching flexibility of each bowl, and of the market as a whole.

The decision of the NCAA to no longer try to prevent unraveling prompted a rapid reorganization of the market, as consortia of bowls and (enlarged) conferences formed to permit later matchings of teams and bowls. Although there have been almost yearly changes in some of the details of how this market reorganization has proceeded (including changes in which teams belong to which football conferences), the major changes can be grouped into three periods, called the Bowl Coalition, the Bowl Alliance, and the Bowl Championship Series. The Bowl Coalition (BC) lasted three years, from 1992 to 1994, and included all major conferences except the Pacific Ten and Big Ten conferences, and all major bowls except the Rose Bowl. In-season unraveling was prevented under the $\mathrm{BC}$, but conference tie-ins existed for the participating conferences and bowls. Conference tie-ins were later eliminated in the Bowl Alliance (BA) era, which lasted from 1995 to 1997 . The BC and BA aimed to create a national championship game whenever one was possible among the participating bowls, conferences, and teams. Finally, the Pacific Ten and Big Ten conferences and the Rose Bowl joined with the Bowl Alliance members to create the Bowl Championship Series (BCS) in 1998. This is the current coalition in place. The number 1 and number 2 teams in the country determined according to the BCS ranking system play a national championship game under the BCS system (details of the coalition eras can be seen in Table 1). The table shows that, starting in 1992, the market steadily reorganized to make the late part of the market increasingly thick, that is, to allow larger numbers of teams to be potentially matched after their final rankings were known.

\section{Measuring efficiency}

- A narrow measure of the welfare generated by a bowl game is the revenue it generates. A broad measure concerns the entertainment delivered to viewers of the game. These are of course connected, as more viewers mean more advertising revenues, and so TV networks pay more for more widely watched games. In the post-1991 era of bowl coalitions, the revenue from the coalition bowls has been equally distributed among the participating conferences. ${ }^{9}$ The revenue accruing to the conferences is divided among the teams in the conference.

We use TV ratings measured by, Nielsen Media Research Company as a proxy for both measures of welfare. A rating point corresponds to $1 \%$ of the entire TV audience in the United States tuning in to watch a game. ${ }^{10}$ We control the change in TV viewer population over years using the percentage system adopted by Nielsen. We obtained the ratings from Nielsen Media Research. We will use these data to investigate what kind of matching maximizes viewership. We will see that a matching that leads to a championship game and to the remaining highly ranked teams being spread among the bowls is more efficient than a matching that divides the teams among the bowls without producing a championship game. Thus, the move toward later matching will turn out to have increased the efficiency of the resulting matches.

\footnotetext{
${ }^{9}$ With two exceptions: (i) the Rose Bowl provides a separate purse for the conferences, and (ii) a second team in the BCS bowls from the same conference brings additional revenue for that conference.

${ }^{10}$ A rating point is calculated for the whole potential TV audience, but not for the fraction of the potential audience currently watching TV. The data for the Nielsen Media Research national ratings service in the United States are collected through electronic measurement meters. These meters are placed in a sample of 5100 households in the United States, randomly selected and recruited by Nielsen Media Research. A meter is placed on each TV set in the sample household. A meter measures two things: what program or channel is being tuned and who is watching. Meters are used to collect audience estimates for broadcast and cable networks, nationally distributed syndicated programs, and satellite distributors. See www.nielsenmedia.com for further information.
} 


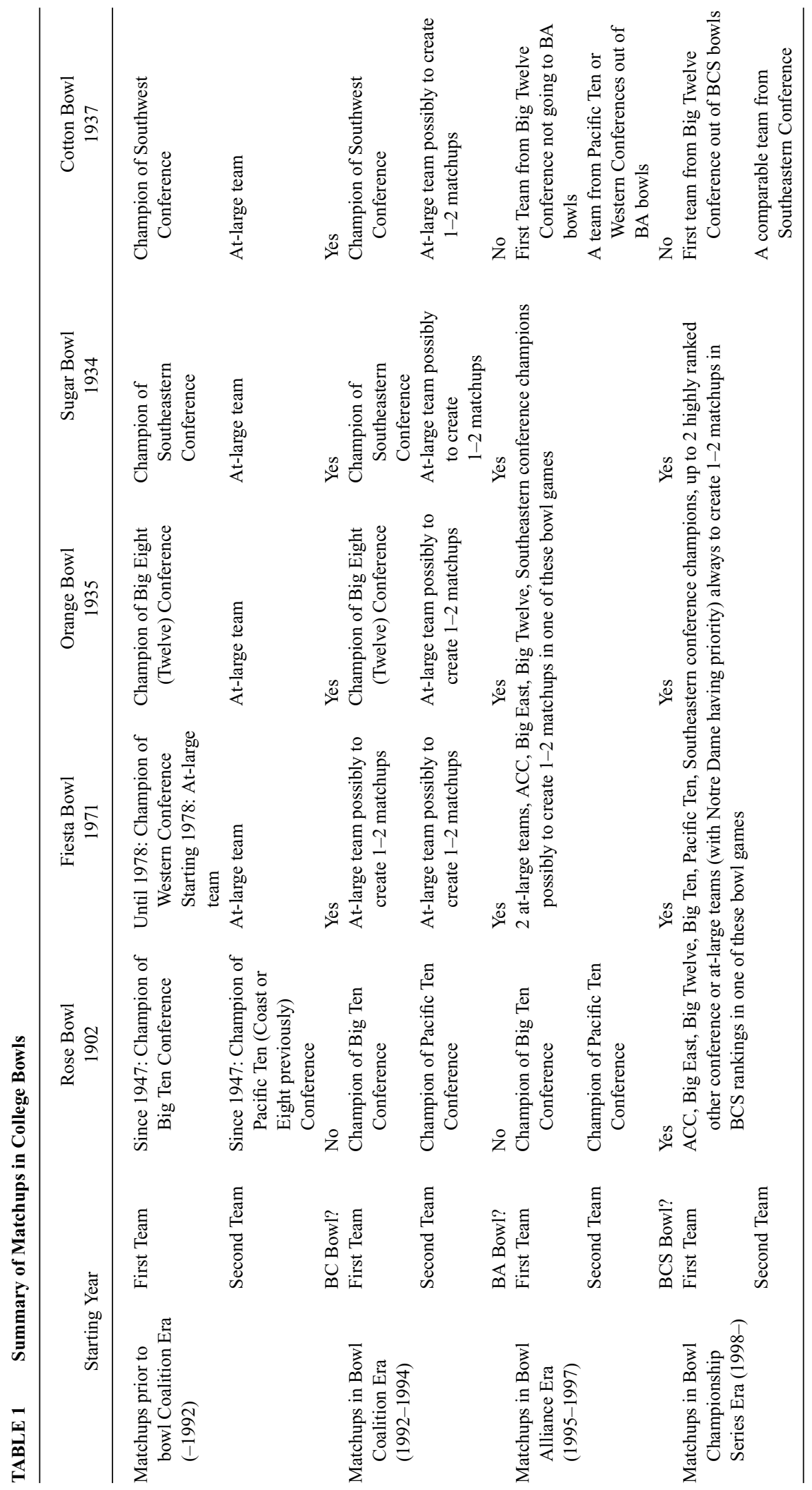


TABLE 2 Probability of Top Two Teams Ending the Regular Season as Top Two in AP Poll

\begin{tabular}{lcccc}
\hline & 1 Week Prior & 2 Weeks Prior & 3 Weeks Prior & 4 Weeks Prior \\
\hline Probability & .690 & .586 & .310 & .345 \\
Standard error & .086 & .091 & .086 & .088 \\
Number of obs. & 29 & 29 & 29 & 29 \\
\hline
\end{tabular}

\section{Data analysis}

- The data consist of the Associated Press (AP) Sports Writers' end-of-regular-season rankings of NCAA division I-A teams that played in the five bowls that were involved in a given year with either the Bowl Coalition (BC: 1992-1994), the Bowl Alliance (BA: 1995-1997), or the Bowl Championship Series (BCS: 1998-2005) (see Table 6 in online Appendix $\mathrm{A}^{11}$ ). ${ }^{12}$ These bowls are the Rose, Fiesta, Orange, Sugar, and Cotton bowls. The data cover all seasons since 1977. As of 1985, we also have the Nielsen ratings for each bowl, the regular season average Nielsen rating for college football games, and the Super Bowl Nielsen rating (see Table 7 in online Appendix A).

Table 2 shows how difficult it is to pick a championship game before the regular season ends. We look one, two, three, and four weeks prior to the end of the regular season for all years in the sample (1977-2005) and find the top two teams in that week (in the AP Sports Writers' Poll). Table 2 shows the probability that these teams will be the top two teams when the regular season ends. The top two teams three and four weeks prior to the end of the regular season will still be the top two teams when the regular season ends only a little over $30 \%$ of the time. These probabilities increase to $59 \%$ and $69 \%$ two weeks and one week prior to the regular season ending, respectively. Hence one to two matchups determined three to four weeks before the end of the regular season (as became common prior to the formation of the Bowl Coalition in 1992) have very little chance of turning into real championship games when the regular season ends.

In the pre-coalition era, a championship game was played only in four of the fifteen years in our sample (see Table 6 in online Appendix A). Note that the lack of championships in the pre-coalition era was not a result of the fact that the number 1 and 2 teams were in bowls other than the ones we are considering. For our entire sample, there are only two years when one of the top two teams did not play in the five bowls we consider: 1984 when the number 1 team (Brigham Young) played in the Holiday Bowl, and 1990 when the number 2 team (Georgia Tech) played in the Florida Citrus Bowl. So the top two teams almost always played in one of the current four BCS bowls over our sample of years. (The Cotton Bowl hosted one of the two top teams only twice: the number 1 team in 1977 and the number 2 team in 1983. $)^{13}$ Therefore, the lack of championship games in our sample is because of in-season unraveling and pre-commitments of the conferences to different bowls.

We next consider how many of the missed championship matchups in the pre-coalition era were because of in-season unraveling, and how many were due to conference commitments. In Table 8 (available in online Appendix A), we inspect whether it was possible to create a national championship bowl that would match the number 1 and number 2 teams in the country according

\footnotetext{
${ }^{11}$ Online Appendix A can be found at homepages.nyu.edu/ gf35/print/online_appendix.pdf.

${ }^{12}$ The AP Sports Writers' Poll is only one of the possible choices. One could also use the USA Today/ESPN Coaches' Poll or one of the many computer rankings. We chose the AP because it is a well-established ranking and for reasons of data availability. We obtained the weekly and end-of-regular-season AP Poll rankings and bowl matchup data from NCAA (2003) and Weekly AP Poll Rankings at 2cuz.com (2003) and SoonerStats.com (2006).

${ }^{13}$ If we confine our attention to the four BCS bowls, in the 11 years prior to 1992 , the number 1 team was missing once, the number 2 team twice, and the number 3 team three times. In contrast, in the 11 years starting in 1992, the number 1,2, and 3 ranked teams at the end of the regular season have always played in one of the four BCS bowls.
} 
TABLE 3 Frequency of Championships

\begin{tabular}{lcc}
\hline & Championship Was Not Possible & Championship Was Possible \\
\hline Pre-coalitions & $0 \%$ (out of 5 years) & $40 \%$ (out of 10 years) \\
Coalitions period & $0 \%$ (out of 6 years) & $100 \%$ (out of 8 years) \\
\hline
\end{tabular}

to the AP Sports Writers' Poll, under different institutional regimes. When the top two teams were in conferences whose champions were pre-committed to participate in different bowls, these two teams would not be matched, even if the bowl selection took place after the regular season was over.

Table 8 shows that, in the pre-coalitions era, in 10 out of the 15 years in question, it was possible to create a championship matchup despite the pre-commitments of conferences to specific bowls. This is because most of the pre-commitments involved semi-closed bowls, meaning that one conference champion and an at-large team could play at the bowl, and many of the most successful teams were at-large teams. ${ }^{14}$ The championship matchup was obtained only in four of the fifteen years. Therefore, a championship matchup was not possible because of pre-season commitments only in five years, thus giving strong indications that the failure to obtain a championship in the other six years was because of in-season unraveling. To the extent that missed championships are the results of in-season unraveling in years where a championship was possible, that effect becomes more prominent in the last seven years prior to the coalitions era. In these seven seasons, a championship game was possible in six seasons and it was played only twice. Table 8 provides strong evidence that in-season unraveling was a big part of the failure to create championship games in these seasons.

The different coalitions that followed had mixed success: the BC produced championships in two of its three years, the BA in only one out of three, and the BCS in five out of eight. Conference-bowl tie-ins prevented championship matchups in the remaining years in the BA and $\mathrm{BC}$ era. Also, there were three years in the BCS era in which the rankings used to determine the BCS championship game selected different top two teams than the AP Sports Writers' Poll. In the BCS era, although a championship game was played in every year, this was determined according to the BCS rankings, while we are counting championships according to the (more widely respected) AP rankings.

By delaying bowl selection until the end of the regular season and gradually removing conference tie-ins, the effect that the coalitions have had on the probability of a championship is clear and can be seen in Table 3. Comparing the proportion of the years when there was a championship, the hypothesis that there were as many prior to 1992 as after can be rejected (twosample test of proportion, one-sided, $5 \%$ level). Similarly, the same conclusion can be reached comparing the BCS years to the pre-1992 era. ${ }^{15}$ Note also that this table highlights the fact that there were no significant differences in the frequency with which championships were possible if one compares the pre-coalitions period to the coalitions period. More specifically, it was not possible five out of fifteen years in the pre-coalitions period versus six out of fifteen years in the coalitions period.

Another effect of the coalitions has been to improve the rankings of the teams playing in the top bowls. For instance, although the Orange and Sugar bowls have had the number 1 and 2

${ }^{14}$ It is noteworthy that with the 1990s and the establishment of the Big East football conference (which in turn initiated the start of the Bowl Coalition era), all major independent teams but Notre Dame joined a conference and left their "independent" status.

${ }^{15}$ One could estimate the effect of the different coalitions on the probability of a championship conditional on a championship being possible via a multinomial probit where there are five possible outcomes defined by whether there is a championship or not and which of the four bowls is hosting it. However, because there has been a championship every year that it was possible during the coalitions era, the coefficient estimate of that regressor would be infinite. 


\section{FIGURE 1}

\section{AVERAGE NORMALIZED NIELSEN RATINGS IN BCS BOWLS}

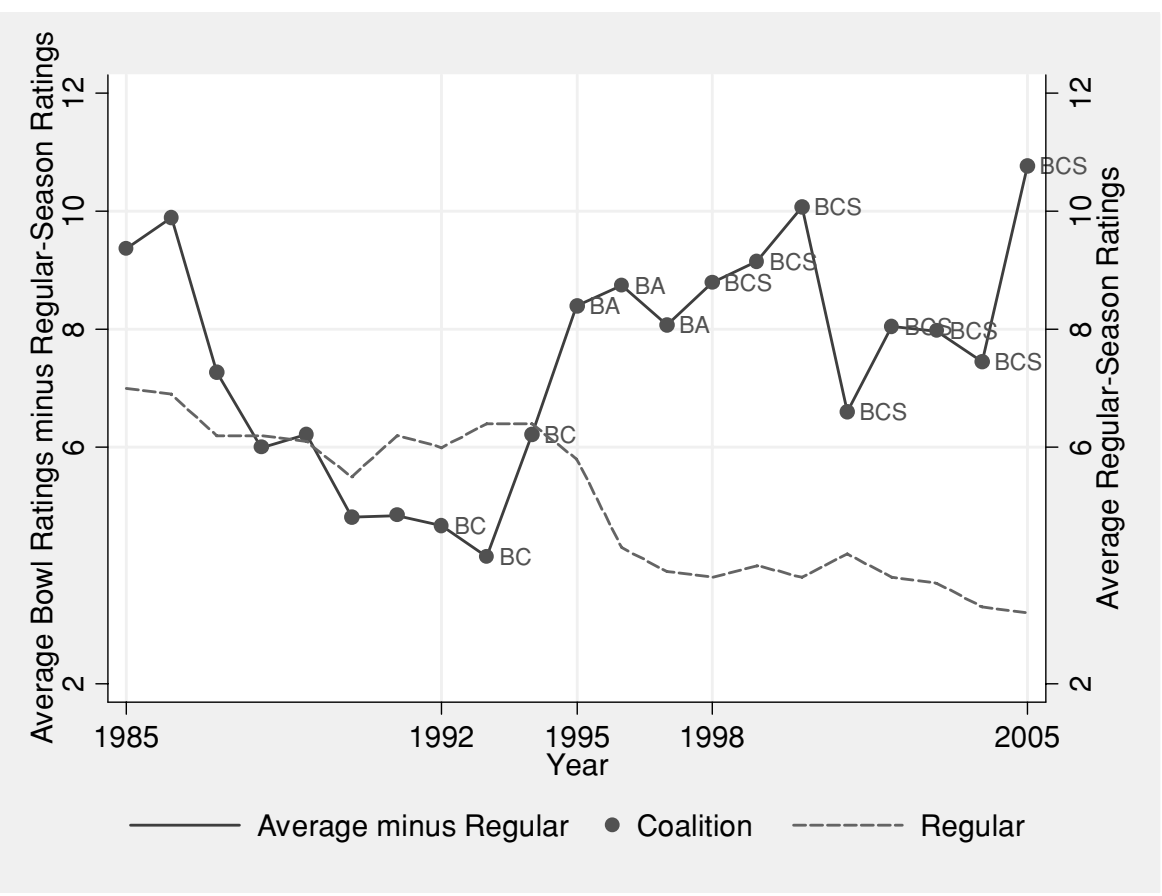

teams play slightly less often since the first coalition (the Orange Bowl has received the number 1 (2) team 7 (5) times in the fifteen years prior to the BC and 4 (2) times in the eleven years after, and these numbers are 3 (6) and 3 (4) for the Sugar Bowl), the Rose and Fiesta bowls have had an important increase: 1 (1) to 4 (3) for the Rose Bowl and 2 (1) to 3 (4) for the Fiesta. Overall, regressions provided in Appendix A in this paper (Table 9) show that the rank of the best and worst teams in the BCS bowls are better than in the period prior to the BC. ${ }^{16}$

In Figure 1, we can see the evolution of the average Nielsen ratings per year in the BCS bowls, normalized by subtracting the average regular-season college football ratings for that year. As Figure 1 indicates, aggregate statistics suggest that the reorganizations after 1992 reversed the declining trend in the relative popularity of bowl games as measured by television viewership. Since the first Bowl Coalition, the fall in ratings in the bowls as compared to the regular season seems to have stopped. ${ }^{17}$ This is confirmed in Table 4, which presents regression estimates of the average Nielsen ratings in the top four bowls (Sugar, Fiesta, Rose, and Orange) on different specifications that indicate the correlation between those coalitions and the ratings controlling for time trends. ${ }^{18}$ The different specifications include Year, which goes from 1 (in 1985) to 18 (2002) or Year interacted with indicator variables for pre-1992 (Pre-Coalitions) or 1992 and above

${ }^{16}$ This can be established directly for the best team by the statistical significance of the BCS in specification 12. For the worst, using estimates from 13, we can reject the joint hypothesis that all the year dummies prior to 1992 equal the estimates for the BCS.

${ }^{17}$ However, it is important to note that the regular-season ratings have been dropping (on average by 0.19 Nielsen ratings point per year over our sample period). This series can also be seen in Figure 1. Note that average regular-season ratings are calculated as the average of all rating points that each game gathers on all markets (i.e., the average of the audiences for all regular-season games as a percentage of all TV sets).

${ }^{18}$ Here (in specifications 1 and 2) the dependent variable is Nielsen ratings; it is not normalized by the ratings of the regular season. Specifications 3 and 4 are similar to 1 and 2, but the dependent variable is the log odds ratio of the Nielsen ratings. Specifications 2 and 4 control for the average ratings of the regular season. 


\begin{tabular}{lccccc}
\hline & \multicolumn{2}{c}{ Average Nielsen Ratings } & & \multicolumn{2}{c}{ Log Odds Ratio } \\
\cline { 2 - 3 } \cline { 6 - 6 } Regressors & Spec. (1) & Spec. $(2)$ & & Spec. $(3)$ & Spec. $(4)$ \\
\hline Year & $-.464^{* *}$ & -.261 & & $-.040^{* *}$ & -.019 \\
& $(.180)$ & $(.217)$ & & $(.017)$ & $(.020)$ \\
BC & .38 & -.588 & & -.014 & -.111 \\
& $(1.397)$ & $(1.481)$ & & $(.129)$ & $(.134)$ \\
BA & $3.563^{*}$ & $4.169^{* *}$ & & $.317^{*}$ & $.378^{* *}$ \\
& $(1.793)$ & $(1.766)$ & & $(.165)$ & $(.160)$ \\
BCS & $5.373^{*}$ & $6.148^{* *}$ & & $.510^{* *}$ & $.588^{* *}$ \\
& $(2.559)$ & $(2.507)$ & & $(.236)$ & $(.227)$ \\
Average Regular Season & & 1.364 & & & .136 \\
Nielsen Ratings & & $(.886)$ & & & $(.080)$ \\
Constant & $15.076^{* * *}$ & 5.669 & & $-1.812^{* * *}$ & $-2.752^{* * *}$ \\
& $(0.928)$ & $(6.174)$ & & $(.085)$ & $(.560)$ \\
Observations & 21 & 21 & & 21 & 21 \\
\hline
\end{tabular}

Standard errors are in parentheses.

* Significant at $10 \% ;{ }^{* *}$ significant at $5 \%$; ${ }^{* * *}$ significant at $1 \%$.

(Coalitions), indicator variables for the different coalitions (BC, BA, BCS), and the regular-season average Nielsen ratings for college football (Specifications 1, 2, 3, 4). The estimations indicate that the fall in ratings has been stopped and have bounced back up (although not to 1985 levels).

Let us now turn to a more systematic analysis of the determinants of viewership at the bowl level. Table 5 reports the determinants of viewership as measured by the Nielsen ratings. The basic estimation equation is

$$
\begin{aligned}
N_{B, Y}= & a+d_{1} C_{B, Y}+d_{2} \text { One }_{B, Y}+b_{1} \text { Average }_{B, Y}+b_{2} \text { Difference }_{B, Y}+b_{3} \text { Best }^{*} U R_{B, Y} \\
& +\cdots d_{3} U_{B, Y}+b_{4} \text { RSN }_{Y}+b_{5} \text { SBN }_{Y}+d_{4} \text { Rose }_{B, Y}+d_{5} \text { Orange }_{B, Y}+d_{6} \text { Fiesta }_{B, Y}+e_{B, Y},
\end{aligned}
$$

where the dependent variable is the Nielsen rating in bowl $B$ in year $Y: N_{B, Y}$. The regressors include two indicator variables: one taking value one if there is a championship and zero otherwise $(C)$ and one taking value one if the best team playing is ranked number 1 and zero otherwise (One). It also includes the average rank of the two teams (Average) and the difference in rank between the worst and best team playing (Difference): both Average and Difference take a value of zero if an unranked team is playing. ${ }^{19}$ There is an indicator variable taking a value of one if a team is unranked and zero otherwise $(U R)$ and a regressor capturing the effect of the ranking of the best of the two teams playing when the opponent is unranked (Best). This structure has the advantage of parsimony while allowing for nonlinear effects for a championship game, having the number 1 team, or having an unranked team playing. ${ }^{20}$ Other regressors include the regular-season average Nielsen ratings $(R S N)$ and the Super Bowl Nielsen rating $(S B N)$, which are intended to capture general attitudes toward football and college football as well as seasons that may be more interesting than others. Finally, indicator variables for four of the five bowls, excluding the Sugar Bowl, are included. Given our limited number of observations, we control for time in three different ways which vary in their parsimony. Clearly, time might be relevant, as other factors may vary over time, such as the television schedule of the bowls. Those are controlled for with either year entered linearly (year - 1984 to be more precise), or blocks of three years (two in the case of 2004-2005) for every year except 1985, or time fixed effects. Allowing for year fixed effects means that regular-season average Nielsen rating and the Super Bowl Nielsen rating have

\footnotetext{
${ }^{19}$ Alternatively, we could have used the rank of the best and worst teams playing as regressors, which is equivalent.

${ }^{20}$ The same specification adding an indicator variable for the cases in which the no. 2 team plays was conducted and indicates that having the no. 2 team playing does not have a nonlinear effect (that dummy variable was not statistically significant).
} 
TABLE 5

Estimates of the Determinants of Nielsen Rating of a Bowl

\begin{tabular}{|c|c|c|c|c|c|c|}
\hline \multirow[b]{2}{*}{ Regressors } & \multicolumn{6}{|c|}{ Nielsen Rating of a Bowl } \\
\hline & Spec. (5) & Spec. (6) & Spec. (7) & Spec. (8) & Spec. (9) & Spec. (10) \\
\hline Championship (no. 1 vs. no. 2 ) & $\begin{array}{l}3.320^{* *} \\
(1.348)\end{array}$ & $\begin{array}{l}3.385^{* *} \\
(1.347)\end{array}$ & $\begin{array}{l}3.751^{* * *} \\
(1.389)\end{array}$ & $\begin{array}{l}3.187^{* *} \\
(1.475)\end{array}$ & $\begin{array}{r}3.335^{*} \\
(1.741)\end{array}$ & $\begin{array}{l}4.969^{* *} \\
(2.075)\end{array}$ \\
\hline No. 1 Ranked Team & $\begin{array}{l}3.166^{* *} \\
(1.357)\end{array}$ & $\begin{array}{l}3.154^{* *} \\
(1.381)\end{array}$ & $\begin{array}{l}2.886^{* * *} \\
(1.050)\end{array}$ & $\begin{array}{c}3.229^{* *} \\
(1.249)\end{array}$ & $\begin{array}{l}2.901^{* *} \\
(1.354)\end{array}$ & $\begin{array}{r}2.290^{*} \\
(1.339)\end{array}$ \\
\hline $\begin{array}{l}\text { Average rank (if unranked } \\
\text { team is not playing) }\end{array}$ & $\begin{array}{l}-.375^{* * *} \\
(.067)\end{array}$ & $\begin{array}{l}-.375^{* * *} \\
(.070)\end{array}$ & $\begin{array}{c}-.404^{* * *} \\
(.103)\end{array}$ & $\begin{array}{r}-.331^{*} \\
(.164)\end{array}$ & $\begin{array}{r}-.382^{*} \\
(.198)\end{array}$ & $\begin{array}{c}-.389^{* *} \\
(.178)\end{array}$ \\
\hline $\begin{array}{l}\text { Difference in Rank (if unranked } \\
\text { team is not playing) }\end{array}$ & $\begin{array}{l}.103 \\
(.066)\end{array}$ & $\begin{array}{l}.107 \\
(.072)\end{array}$ & $\begin{array}{l}.137 \\
(.098)\end{array}$ & $\begin{array}{r}-.106 \\
(.110)\end{array}$ & $\begin{array}{r}-.083 \\
(.139)\end{array}$ & $\begin{array}{r}-.074 \\
(.158)\end{array}$ \\
\hline $\begin{array}{l}\text { Rank of Best Team (if unranked } \\
\text { team is playing) }\end{array}$ & $\begin{array}{r}-.006 \\
(.035)\end{array}$ & $\begin{array}{r}-.009 \\
(.046)\end{array}$ & $\begin{array}{r}-.059 \\
(.225)\end{array}$ & $\begin{array}{r}.345^{*} \\
(.195)\end{array}$ & $\begin{array}{l}.452^{* *} \\
(.189)\end{array}$ & $\begin{array}{r}.638^{*} \\
(.355)\end{array}$ \\
\hline Unranked Team & $\begin{array}{c}-6.262^{* * *} \\
\quad(.848)\end{array}$ & $\begin{aligned}-5.934^{* * *} & \\
& (.762)\end{aligned}$ & $\begin{array}{c}-6.526^{* *} \\
(2.854)\end{array}$ & $\begin{array}{l}-8.891^{* * *} \\
(2.629)\end{array}$ & $\begin{array}{c}-10.674^{* * *} \\
(2.964)\end{array}$ & $\begin{array}{c}-13.666^{* * *} \\
(4.337)\end{array}$ \\
\hline Regular-Season College Football & -.403 & .724 & & $-1.657^{* * *}$ & -1.177 & \\
\hline Average Nielsen Rating & $(.584)$ & $(.454)$ & & $(.536)$ & $(.966)$ & \\
\hline Super Bowl's Nielsen Rating & $\begin{array}{c}.223 \\
(.132)\end{array}$ & $\begin{array}{l}.028 \\
(.227)\end{array}$ & & $\begin{array}{l}.254^{*} \\
(.142)\end{array}$ & $\begin{array}{l}.098 \\
(.340)\end{array}$ & \\
\hline Fiesta Bowl & $\begin{array}{l}.561 \\
(.895)\end{array}$ & $\begin{array}{l}.557 \\
(.931)\end{array}$ & $\begin{array}{l}.578 \\
(.862)\end{array}$ & $\begin{array}{c}2.251 \\
(1.389)\end{array}$ & $\begin{array}{c}2.699^{*} \\
(1.445)\end{array}$ & $\begin{array}{c}2.480 \\
(1.665)\end{array}$ \\
\hline Orange Bowl & $\begin{array}{c}1.147 \\
(1.103)\end{array}$ & $\begin{array}{c}1.163 \\
(1.133)\end{array}$ & $\begin{array}{l}1.158 \\
(.873)\end{array}$ & $\begin{array}{l}3.521^{* * *} \\
(1.131)\end{array}$ & $\begin{array}{l}3.604^{* * *} \\
(1.099)\end{array}$ & $\begin{array}{c}3.353^{* *} \\
(1.502)\end{array}$ \\
\hline Rose Bowl & $\begin{array}{l}4.929^{* * *} \\
(.998)\end{array}$ & $\begin{array}{l}4.940^{* * *} \\
(1.025)\end{array}$ & $\begin{array}{l}4.911^{* * *} \\
(.857)\end{array}$ & $\begin{array}{l}8.972^{* * *} \\
(1.397)\end{array}$ & $\begin{array}{l}9.380^{* * *} \\
(1.497)\end{array}$ & $\begin{array}{l}9.000^{* * * *} \\
(2.224)\end{array}$ \\
\hline Cotton Bowl & $\begin{array}{l}-.402 \\
(1.008)\end{array}$ & $\begin{array}{l}-.425 \\
(1.045)\end{array}$ & $\begin{array}{r}-.165 \\
(.993)\end{array}$ & $\begin{array}{r}-1.314 \\
(1.709)\end{array}$ & $\begin{array}{l}-.738 \\
(2.078)\end{array}$ & $\begin{array}{l}-.203 \\
(2.075)\end{array}$ \\
\hline Year & $\begin{array}{c}-.183 \\
(.112)\end{array}$ & & & $\begin{array}{c}-.427^{* * *} \\
(.103)\end{array}$ & & \\
\hline $1986-1988$ & & $\begin{array}{c}-2.149 \\
(1.641)\end{array}$ & & & $\begin{array}{r}-2.580 \\
(2.439)\end{array}$ & \\
\hline 1989-1991 & & $\begin{array}{r}-3.496^{*} \\
(1.853)\end{array}$ & & & $\begin{array}{l}-4.493 \\
(3.374)\end{array}$ & \\
\hline 1992-1994 & & $\begin{array}{c}-4.309^{* * *} \\
(.979)\end{array}$ & & & $\begin{array}{c}-5.107^{* *} \\
(2.210)\end{array}$ & \\
\hline 1995-1997 & & $\begin{array}{r}-2.343^{*} \\
(1.214)\end{array}$ & & & $\begin{array}{c}-5.636^{* *} \\
(2.018)\end{array}$ & \\
\hline $1998-2000$ & & $\begin{array}{l}-1.66 \\
(1.938)\end{array}$ & & & $\begin{array}{r}-6.131^{*} \\
(3.462)\end{array}$ & \\
\hline $2001-2003$ & & $\begin{array}{c}-2.942 \\
(1.981)\end{array}$ & & & $\begin{array}{c}-9.003^{* *} \\
(3.389)\end{array}$ & \\
\hline 2004-2005 & & $\begin{array}{c}-2.268 \\
(2.283)\end{array}$ & & & $\begin{array}{c}-8.147^{* *} \\
(3.905)\end{array}$ & \\
\hline Constant & $\begin{array}{c}6.296 \\
(6.625)\end{array}$ & $\begin{array}{c}9.439 \\
(11.190)\end{array}$ & & $\begin{array}{l}16.764^{* *} \\
(7.485)\end{array}$ & $\begin{array}{c}21.275 \\
(15.944)\end{array}$ & \\
\hline Team dummies & No & No & No & Yes & Yes & Yes \\
\hline Time fixed effects & No & No & Yes & No & No & Yes \\
\hline Observations & 105 & 105 & 105 & 95 & 95 & 95 \\
\hline$R^{2}$ & .730 & .750 & .760 & .890 & .900 & .910 \\
\hline
\end{tabular}

Robust standard errors are in parentheses.

* Significant at $10 \%$; ${ }^{* *}$ significant at $5 \%$; ${ }^{* * *}$ significant at $1 \%$.

to be dropped. Specifications 8-10 include team-specific effects which control for the intrinsic popularity of some teams it does; however, reduce sample size, as there are teams that only play once in a bowl in our sample.

The team dummies are jointly statistically significant in all three specifications $(p<0.1)$. This does not, however, allow us to distinguish whether good teams, which happen to be famous 
most of the time, bring high ratings, or whether famous teams, which happen to be good most of the time, are the cause of better ratings. The time fixed effects are jointly statistically significant ( $\mathrm{p}$ value $=0.055)$ in specification 7 but not jointly statistically significant in specification $10(\mathrm{p}$ value $=0.201),{ }^{21}$ but the null hypothesis that the time dummies in specifications 6 and 9 are all equal to zero can be rejected at the $1 \%$ level. The average rank has the expected sign and is statistically significant in all six specifications. The difference in rank is never statistically significant. Furthermore, its sign is different when team fixed effects are included versus when they are not. When team fixed effects are included, the estimates imply fully assortative matching, that is that the best team plays the second best, the third plays the fourth, and so on, but the other three estimates (without controls for team fixed effects) suggest that the best team plays the second best while the third, fourth, and fifth best team each play in separate bowls. Note that a positive sign on the difference regressor is not as strange as it might appear; it does not mean that a bowl owner would prefer the worse of its two teams to have the worst possible rank. Rather, it means two things. First, the effect of having a championship game dominates the effect of the difference regressor. Therefore, hosting a championship game is still very desirable for obtaining high ratings, even with a positive sign on the difference regressor. Second, if offered a choice between a 4 versus 5 matchup or 3 versus 6 , a bowl owner should take the latter. However, even the estimates not controlling for team fixed effects suggest that a bowl owner should prefer a 3 versus 5 matchup to a 3 versus 6 one. That is, the effect on the average dominates the one on the difference. The estimate of the effect of having an unranked team is, as expected, negative. The rank of the best team when an unranked team is playing has the expected sign without team fixed effects but then is not statistically significant, and has a positive sign when team fixed effects are included. Note that in the data for those regressions, only four bowls included an unranked team and thus those results could be driven by a few historical rivalries. A key result from these estimations is that the effect of a championship is statistically significant (the sum of the coefficient estimate on the championship and no. 1 dummies is statistically different from 0 at the $1 \%$ level in all six specifications).

Because Nielsen ratings are given as percentages, simply using OLS for estimation can lead to problems (for instance, predictions outside the range of possible values). Using appropriate methods for fractional dependent variables does not qualitatively affect the results. This was established by transforming the dependent variable into a log odds ratio. That is, the estimates keep the same sign, and in most cases the same are statistically significant. These estimates are available in Appendix B in Table 10.

An additional concern could be the potential endogeneity of the start of the Bowl Coalition. That is, the Bowl Coalition could have been created as a reaction to the declining ratings (instead of the unraveling problem), which would bias our estimates. To address this concern, we reestimate the main specifications on data prior to the start of the coalitions. However, because of the smaller sample, we cannot control for team fixed effects. The results are similar to those for the same specifications over the full sample. The only differences (for the four main regressors: $\mathrm{C}$, One, Average, and Difference) are the following. $\mathrm{C}$ is not statistically significant in the equivalent to specification 7. Average is not statistically significant in the equivalents to 6 and 7 and in the equivalent to 5 . Difference is positive (as in 5) and statistically significant. ${ }^{22}$

${ }^{21}$ Allowing for year fixed effects allows us to control for the fact that in different years, the schedule of bowls was different (when different bowls were played). This could be important, as bowls sometimes overlapped. Thus, the fact that the championship indicator variable still has a positive and statistically significant coefficient estimate indicates that we are not confounding the effect of scheduling with that of championships. We also estimate regressions where we control for the number of bowls played on the same day as the bowl in consideration. If we include a regressor which gives the number of bowls (excluding the one being considered) on the same day in specifications 5-10, the coefficient estimate is always negative but not significant in all but one case ( $\operatorname{spec} 8$ ). The average number of bowls on the same day as the 5 bowls in our data does not change much with the coalitions (it is 4.725 before the coalitions start and 4.186 after that).

${ }^{22}$ The estimates for the pre-coalitions period are available in online Appendix C in Table 11, which can be found at homepages.nyu.edu/ $\sim$ gf $35 /$ print/online_appendix.pdf. 
Efficiency. Figure 1 suggests that the bowl consortia, which established a rotating championship game, increased the attractiveness of the bundle of bowl games.

Let us now consider how the matching of teams affects the Nielsen ratings. We will focus on estimates from specification 10. Start from the hypothetical case in which a bowl can host a game between teams ranked 3 and 5. Increasing the rank of the best team by 1 would result in a change in ratings of $-0.389 \times(3.5-4)-0.074 \times(3-2)=0.120$. The average Nielsen rating (in the BCS bowls) is 12.59; thus, this represents an increase of about $1 \%$ of the average. The effect of improving the worst team by one rank, from 5 to 4 , would be an increase of 0.268 points or a little above $2 \%$ of the average. Although small changes in Nielsen ratings might represent serious sums of money, these look like modest changes. ${ }^{23}$ However, when increasing a team's ranking by only one rank means getting the no. 1 team, the effect is large: $2.290-0.389 \times(-0.5)-0.074 \times$ $(-1)=2.558$, or $20.32 \%$ of the average. Similarly, going from a no. 1 versus no. 3 match to a championship (1 versus 2 ) game would increase ratings by $4.969-0.389 \times(-0.5)-0.074 \times$ $(-1)=5.237$, which represents $41.60 \%$ of the average rating.

A more concrete counterfactual can be obtained by estimating the Nielsen ratings as though the bowl matchups in the coalitions era were realized in the pre-coalitions era. For example, if the matchups in the four BCS bowls in 1998 (first year of BCS) were actually realized in 1991 (the last year before coalitions), we can compute the counterfactual average rating per bowl. The counterfactual rating is calculated by removing the time fixed effect of the relevant year and instead giving the 1991 value. We did this for every year of the BCS era, that is, from 1998 on, and found that the average counterfactual rating would be $12.75 .{ }^{24}$ The actual average of the Nielsen ratings of the now BCS bowls in 1991 was 11.05 . This represents a $15.37 \%$ increase in average Nielsen ratings.

This is not a negligible increase from a financial point of view. Using data from the bowls aired in 2006 (Rose, Orange, Fiesta, and Sugar), we can estimate that the cost per rating point for a 30 second ad was $\$ 39,163.97$ (Image Impact, 2006). ${ }^{25}$ Thus, an overall increase in ratings of 6.8 points (four times the average increase of 1.7 points per bowl), as suggested by the counterfactual above, would translate into $\$ 266,315$ increased revenues for each 30 seconds of television ad. This suggests a difference in revenue in the millions of dollars in television advertising as a result of solely having a championship. For example, in the 2006 BCS championship game (played in January 2007) there were approximately 107.5 blocks of 30 second ads. Of course, we do not know how many television ads were presented in the BCS bowls of previous years, or to what extent those vary per bowl, but using this as a guide, it suggests an increase in revenues of $\$ 28,628,863$ for the four bowls combined. ${ }^{26}$ (In 2004, the television revenues of the BCS bowls were reported to be in the neighborhood of $\$ 100$ million; see, e.g., Drape, 2004). Furthermore, this is a clear lower bound on the value of ratings, as it neglects the value of logo placements on the stadiums, the fields, the uniforms, and on radio. The combined value of logo placements for these four bowls in 2006 has been estimated to be worth between $\$ 20$ and $\$ 30$ million per bowl (Image Impact, 2006). This is not even considering the other benefits of matching late, such as the ability to pick better teams for all bowl games.

Because revenues generated by the bowls are shared almost equally among the members of a coalition, a market organization that allows sufficiently late matching to allow a championship can have beneficial effects on average for every member of the coalition.

${ }^{23}$ We have compared increases in only one position, however,. Matching 2 versus 3 instead of for example, 12 versus 13 (as in the 1981 Rose Bowl) would yield an increase in ratings of 3.89 , or $30.90 \%$.

${ }^{24}$ Using the log odds ratio specification suggests an even greater effect of 13.53 .

${ }^{25}$ According to the Image Impact, 2006 BCS press release, retrieved from www.imageimpact.tv/WhoWeAre/ PressRelease.asp on 3/4/2006.

${ }^{26}$ The data were gathered by the authors. This is counting from the block of ads before the game starts until the block of ads after the game ends. It consists mainly of 30 second ads although it also includes a few ads of 15 seconds. 


\section{Conclusion}

- Prior to 1992, the matching of football teams to post-season college bowls had become deeply unraveled, with teams and bowls making commitments with as many as four games remaining in the regular season. This resulted in considerable loss of information: as Table 2 shows, there is only a $31 \%$ chance that an apparent championship match made four weeks early will in fact remain a championship match by the time the game is played.

In 1992, the market began a series of reorganizations into consortia of bowls and conferences that have allowed matching to occur later, when more reliable information on rankings is available, and among a broader pool of conferences and teams. ${ }^{27}$ This has led to more championship games, which in turn has led to more viewers. To the extent that the number of viewers is a measure of the output of this industry, this allows us to see how changes in the organization of the market led to improved matching, and substantially increased output and efficiency. The evidence suggests that further changes in market organization, if they increase the likelihood of producing a "national champion," might achieve further gains. ${ }^{28}$

This article began with the observation that many markets have unraveled, and that some have reorganized to prevent unraveling and to promote a thick market at a late time. The reorganization of the football bowl market allows this to be seen clearly. It created a more centralized allocation process that increased efficiency by delaying the market so that it could operate after the end of regular-season rankings were known, and by allowing matches to be made among the highestranked teams. This increased the efficiency of the resulting matchings.

\section{Appendix A}

- Appendix A can be found at homepages.nyu.edu/ gf35/print/online_appendix.pdf.

\section{Appendix B}

- In what follows, we inspect the ranking of teams picked by top bowls throughout the season. For the BCS era we use the Rose, Orange, Sugar, and Fiesta (namely four BCS) bowls, for the BA era we use the Orange, Sugar, and Fiesta (namely three BA) bowls, for the BC era we use the Orange, Sugar, Fiesta, and Cotton (namely four BC) bowls, and for the decentralized era we use the BC bowls, as well. We exclude the Rose Bowl in all periods except the BCS era, as it used to select champions of two conferences automatically.

Table 9 reports how the ranking of the best and worst team in these bowls evolves over time and with the different coalitions. It also looks at the determinants of a championship game (a bowl involving the 1 and 2 ranked teams). Specifications 11, 13, and 14 are estimated by OLS. ${ }^{29}$ For the Best regressions, specifications 11 and 13, the dependent variable is the rank of the best-ranked team in a given bowl-year. For the Worst regression, specification 14, the dependent variable is the rank of the worst-ranked team in a given bowl-year. For the Best and Worst regressions, the regressors are dummies for different time periods (blocks of three years) and, as of 1992, dummies indicating the different coalitions for bowls that were part of them and a dummy for bowls that are not part of a coalition after 1992 (this represents the Rose Bowl between 1992 and 1995, and the Cotton Bowl from then on). The excluded category is the three years prior to the first coalition (1989-1991). For the Best regression (11), the time dummies between 1977 and 1988 are not jointly statistically significant (at 10\% level), and thus we report specification 13, which excludes those.

Looking at Table 9, specification 13 is suggestive of the fact that since the BCS has been instated, bowls that are members of it have showcased a best team with a better ranking than before $1992 .{ }^{30}$ On the other hand, neither the BC nor the BA seems to have had a significant impact on the rank of the best team. Clearly, bowls that have not been part of

\footnotetext{
${ }^{27}$ Further reorganization in the same direction is presently being contemplated. Most recently, it has been announced that a fifth bowl will be added to the BCS (Drape, 2004).

${ }^{28}$ Such changes might be in the direction of enlarged consortia, or might be in the direction of a series of playoff games, as in some other sports.

${ }^{29}$ All regressions adjust standard errors to correct for possible correlation within bowls that took place the same year (see StataCorp, 2001 for details of the specific correction used).

${ }^{30}$ Clearly the impact of time versus the BCS is hard to disentangle. Two points are worth noting, however. First, a Wald test of the joint statistical significance of the time dummies in (11) cannot reject the hypothesis that they are equal to zero. Second, if we compare a specification with the time dummies but without the BCS dummy to one with the BCS dummy but without the time dummies, as in (12), the one with the BCS dummy has a slightly larger $R^{2}$.
} 
TABLE 9 Evolution of Ranking of the Best and Worst Teams in Each Bowl Matchup

\begin{tabular}{lccc}
\hline & \multicolumn{2}{c}{ Best } & Worst \\
\cline { 2 - 4 } Regressors & Spec. (11) & Spec. (12) & Spec. (13) \\
\hline \multirow{2}{*}{$1977-1979$} & -0.6 & & -2.267 \\
& $(1.312)$ & & $(1.990)$ \\
$1980-1982$ & -0.2 & & -1.867 \\
& $(1.259)$ & & $(1.983)$ \\
$1983-1985$ & 0.333 & & 0.867 \\
& $(1.394)$ & & $(2.299)$ \\
$1986-1988$ & -0.467 & & $-3.667^{*}$ \\
& $(1.330)$ & 0.37 & $(1.943)$ \\
BC (1992-1994) & 0.183 & $(1.125)$ & -0.95 \\
& $(1.669)$ & -0.102 & -0.533 \\
BA (1995-1997) & -0.289 & $(0.397)$ & $(2.369)$ \\
& $(1.283)$ & $-1.068^{* * *}$ & -2.669 \\
BCS (1998-2005) & -1.254 & $(0.362)$ & $(1.993)$ \\
& $(1.272)$ & $3.885^{* *}$ & $6.094^{* *}$ \\
Not BC, Not BA, & $3.698^{*}$ & $(1.542)$ & $(2.547)$ \\
Not BCS after 1992 & $(1.983)$ & $4.880^{* * *}$ & $11.200^{* * *}$ \\
Constant & $5.067^{* * *}$ & $(0.310)$ & $(1.907)$ \\
Observations & $(1.258)$ & 145 & 145 \\
\hline
\end{tabular}

Robust standard errors are in parentheses.

${ }^{*}$ Significant at $10 \% ;{ }^{* *}$ significant at $5 \%$; ${ }^{* * *}$ significant at $1 \%$.

the different coalitions, the Rose Bowl during the $\mathrm{BC}$ and the Cotton Bowl since the $\mathrm{BA}$, have been doing worst, that is, their best team was not as good, when comparing to the years prior to 1992.

For the results for the Worst team, specification 14, one result in particular stands out: with the exception of 19831985, all time period dummies (1977-1988) and coalition dummies (BC, BA, BCS) have a negative coefficient estimate. This indicates that for the 1989-1991 and 1983-1985 time periods, the worst team in any matchup had the worst ranking of all time periods. In particular, the 1986-1988 period was statistically significantly better than 1989-1991. This sharp decline in quality in the top bowls is suggestive of the reasons that prompted attempts at reorganizing the market. Again we can see that the bowls excluded from the post-1992 coalitions have not been doing well.

Most results are robust to alternative specifications: that is, using an ordered logit or ordered probit to estimate the best and worst team specifications. One fact that might be of concern is that we are describing the evolution of the matchups but the Rose Bowl prior to 1998 had pre-arrangements to automatically take conference champions (no at large

TABLE 10 Estimates of the Determinants of Nielsen Rating of a Bowl: Log Odds Ratio

\begin{tabular}{lcccccc}
\hline & \multicolumn{7}{c}{ Log Odds Ratio of Nielsen Rating of a Bowl } \\
\cline { 2 - 7 } & $\begin{array}{c}\text { Spec. } \\
\text { Regressors }\end{array}$ & $\begin{array}{l}\text { Spec. } \\
\text { (5.1) }\end{array}$ & $\begin{array}{l}\text { Spec. } \\
(6.1)\end{array}$ & $\begin{array}{c}\text { Spec. } \\
(7.1)\end{array}$ & $\begin{array}{c}\text { Spec. } \\
(9.1)\end{array}$ & $\begin{array}{c}\text { Spec. } \\
(10.1)\end{array}$ \\
\hline Championship & $.257^{* *}$ & $.270^{* *}$ & $.313^{* *}$ & 0.24 & 0.283 & $.515^{* *}$ \\
$\quad$ no. 1 vs. no. 2) & $(0.104)$ & $(0.110)$ & $(0.156)$ & $(0.143)$ & $(0.187)$ & $(0.249)$ \\
No. 1 Ranked Team & 0.208 & 0.204 & 0.167 & 0.225 & 0.176 & 0.082 \\
& $(0.129)$ & $(0.130)$ & $(0.118)$ & $(0.163)$ & $(0.176)$ & $(0.160)$ \\
Average Rank (if unranked & $-.051^{* * *}$ & $-.051^{* * *}$ & $-.055^{* * *}$ & $-.047^{*}$ & $-.050^{*}$ & $-.052^{* *}$ \\
$\quad$ team is not playing) & $(0.009)$ & $(0.010)$ & $(0.012)$ & $(0.023)$ & $(0.025)$ & $(0.021)$ \\
Difference in Rank (if unranked & 0.012 & 0.012 & 0.015 & -0.008 & -0.007 & -0.002 \\
$\quad$ team is not playing) & $(0.008)$ & $(0.009)$ & $(0.011)$ & $(0.015)$ & $(0.019)$ & $(0.019)$ \\
Rank of Best Team (if unranked & -0.001 & -0.001 & -0.007 & 0.038 & $.047^{*}$ & 0.072 \\
$\quad$ team is playing) & $(0.006)$ & $(0.008)$ & $(0.025)$ & $(0.026)$ & $(0.025)$ & $(0.042)$ \\
Unranked Team & $-.952^{* * *}$ & $-.923^{* * *}$ & $-1.007^{* * *}$ & $-1.223^{* * *}$ & $-1.397^{* * *}$ & $-1.852^{* * *}$ \\
& $(0.124)$ & $(0.129)$ & $(0.321)$ & $(0.354)$ & $(0.339)$ & $(0.520)$ \\
\hline
\end{tabular}




\begin{tabular}{|c|c|c|c|c|c|c|}
\hline \multirow[b]{2}{*}{ Regressors } & \multicolumn{6}{|c|}{ Log Odds Ratio of Nielsen Rating of a Bowl } \\
\hline & $\begin{array}{l}\text { Spec. } \\
(5.1)\end{array}$ & $\begin{array}{l}\text { Spec. } \\
(6.1)\end{array}$ & $\begin{array}{l}\text { Spec. } \\
(7.1)\end{array}$ & $\begin{array}{l}\text { Spec. } \\
(8.1)\end{array}$ & $\begin{array}{l}\text { Spec. } \\
(9.1)\end{array}$ & $\begin{array}{l}\text { Spec. } \\
(10.1)\end{array}$ \\
\hline $\begin{array}{l}\text { Regular-Season College } \\
\text { Football }\end{array}$ & -0.038 & 0.061 & & $-.160^{* *}$ & -0.121 & \\
\hline Average Nielsen Rating & $(0.055)$ & $(0.048)$ & & $(0.069)$ & $(0.110)$ & \\
\hline Super Bowl's Nielsen Rating & $\begin{array}{c}0.013 \\
(0.013)\end{array}$ & $\begin{array}{c}-0.003 \\
(0.024)\end{array}$ & & $\begin{array}{c}0.018 \\
(0.014)\end{array}$ & $\begin{array}{l}0 \\
(0.036)\end{array}$ & \\
\hline Fiesta Bowl & $\begin{array}{c}0.071 \\
(0.094)\end{array}$ & $\begin{array}{l}0.07 \\
(0.097)\end{array}$ & $\begin{array}{c}0.074 \\
(0.097)\end{array}$ & $\begin{array}{l}0.273 \\
(0.179)\end{array}$ & $\begin{array}{r}.314^{*} \\
(0.182)\end{array}$ & $\begin{array}{c}0.308 \\
(0.199)\end{array}$ \\
\hline Orange Bowl & $\begin{array}{c}0.121 \\
(0.122)\end{array}$ & $\begin{array}{l}0.123 \\
(0.124)\end{array}$ & $\begin{array}{c}0.123 \\
(0.098)\end{array}$ & $\begin{array}{l}.377^{* *} \\
(0.158)\end{array}$ & $\begin{array}{l}.385^{* *} \\
(0.161)\end{array}$ & $\begin{array}{r}.361^{*} \\
(0.180)\end{array}$ \\
\hline Rose Bowl & $\begin{array}{l}.500^{* * * *} \\
(0.100)\end{array}$ & $\begin{array}{l}.501^{* * *} \\
(0.103)\end{array}$ & $\begin{array}{l}.499^{* * *} \\
(0.096)\end{array}$ & $\begin{array}{l}.834^{* * *} \\
(0.151)\end{array}$ & $\begin{array}{l}.897^{* * *} \\
(0.175)\end{array}$ & $\begin{array}{l}.832^{* * *} \\
(0.266)\end{array}$ \\
\hline Cotton Bowl & $\begin{array}{c}-0.104 \\
(0.125)\end{array}$ & $\begin{array}{c}-0.107 \\
(0.130)\end{array}$ & $\begin{array}{c}-0.073 \\
(0.112)\end{array}$ & $\begin{array}{c}-0.175 \\
(0.218)\end{array}$ & $\begin{array}{c}-0.12 \\
(0.247)\end{array}$ & $\begin{array}{c}-0.008 \\
(0.249)\end{array}$ \\
\hline Year & $\begin{array}{l}-.019^{*} \\
(0.010)\end{array}$ & & & $\begin{array}{l}-.043^{* * *} \\
(0.012)\end{array}$ & & \\
\hline 1986-1988 & & $\begin{array}{c}-0.188 \\
(0.151)\end{array}$ & & & $\begin{array}{c}-0.286 \\
(0.250)\end{array}$ & \\
\hline 1989-1991 & & $\begin{array}{c}-0.319 \\
(0.186)\end{array}$ & & & $\begin{array}{c}-0.463 \\
(0.336)\end{array}$ & \\
\hline 1992-1994 & & $\begin{array}{l}-.407^{* * *} \\
(0.109)\end{array}$ & & & $\begin{array}{l}-.523^{* *} \\
(0.233)\end{array}$ & \\
\hline 1995-1997 & & $\begin{array}{l}-.233^{* *} \\
(0.108)\end{array}$ & & & $\begin{array}{l}-.555^{* *} \\
(0.211)\end{array}$ & \\
\hline $1998-2000$ & & $\begin{array}{c}-0.172 \\
(0.171)\end{array}$ & & & $\begin{array}{l}-.633^{*} \\
(0.362)\end{array}$ & \\
\hline $2001-2003$ & & $\begin{array}{c}-0.301 \\
(0.177)\end{array}$ & & & $\begin{array}{l}-.940^{* *} \\
(0.353)\end{array}$ & \\
\hline 2004-2005 & & $\begin{array}{c}-0.284 \\
(0.217)\end{array}$ & & & $\begin{array}{l}-.907^{*} \\
(0.438)\end{array}$ & \\
\hline Constant & $\begin{array}{c}-2.150^{* * *} \\
(0.655)\end{array}$ & $\begin{array}{r}-1.904^{*} \\
(1.094)\end{array}$ & & $\begin{array}{c}-1.23 \\
(0.748)\end{array}$ & $\begin{array}{c}-0.629 \\
(1.644)\end{array}$ & \\
\hline Team dummies & No & No & No & Yes & Yes & Yes \\
\hline Time fixed effects & No & No & Yes & No & No & Yes \\
\hline Observations & 105 & 105 & 105 & 95 & 95 & 95 \\
\hline
\end{tabular}

Robust standard errors are in parentheses.

${ }^{*}$ Significant at $10 \%$; ${ }^{* *}$ significant at $5 \%$; ${ }^{* * *}$ significant at $1 \%$.

selection). Thus, there is no sense in which, for instance, market conditions make them "go early" in some years. Hence the specifications of Table 9 were reestimated using alternative samples: that is, excluding the Rose Bowl prior to 1998. The results are robust to those changes. Estimates are available from the authors.

Table 10 replicates specifications $5-10$ of Table 5 (in the text) using the log odds ratio as the dependent variable.

\section{Appendix C}

- Appendix C can be found at homepages.nyu.edu/ gf35/print/online_appendix.pdf.

\section{References}

Avery, C., Jolls, C., Posner, R.A., And Roth, A.E. “The Market for Federal Judicial Law Clerks.” University of Chicago Law Review, Vol. 68 (2001), pp. 793-902.

— - Fairbanks, A., And Zeckhauser, R. Early Admissions Game. Cambridge, Mass.: Harvard University Press, 2003. , _ _ AND —_. "The New Market for Federal Judicial Law Clerks." University of Chicago Law Review, 2007, forthcoming. 
BARnhart, T. "Bowl Rush over Early This Year Deals May Shut out Teams, Championship." Atlanta Journal, Atlanta Constitution, November 15, 1989.

Drape, J. "B.C.S. Adds Fifth Game and Access for Have-Nots." New York Times, March 1, 2004. Retrieved from www.nytimes.com/2004/03/01/sports/ncaafootball/01BCS.html?ex=1079141503\&ei=1\&en=2e9da875f3164d3a.

HARIG, B. “Orange Bowl in Line for No. 1 Matchup Series: Analysis.” St. Petersburg Times, November 11, 1990.

Haruvy, E., Roth, A.E., And Ünver, M.U. "The Dynamics of Law-Clerk Matching: An Experimental and Computational Investigation of Proposals for Reform of the Market.” Journal of Economic Dynamics and Control, Vol. 30 (2006), pp. $457-486$.

Image Impact. “2006 Bowl Championship Series Press Release.” Retrieved from www.imageimpact.tv/WhoWeAre/ PressRelease.asp on 3/4/2006.

Kagel, J.H., AND Roth, A.E. “The Dynamics of Reorganization in Matching Markets: A Laboratory Experiment Motivated by a Natural Experiment.” Quarterly Journal of Economics, Vol. 115 (2000), pp. 201-235.

Kesten, O. "On Two Kinds of Manipulation for Two-Sided Matching Markets.” Working Paper, 2005.

KoJIMA, F. "When Can Manipulations Be Avoided in Two-Sided Matching Markets? Maximal Domain Results.” Working Paper, 2006.

Li, H. And Rosen, S. "Unraveling in Matching Markets.” American Economic Review, Vol. 88 (1998), pp. 371-387.

- AND SuEN, W. "Risk Sharing, Sorting, and Early Contracting." Journal of Political Economy, Vol. 108 (2000), pp. 1058-1091.

— AND SuEn, W. "Self-Fulfilling Early-Contracting Rush.” International Economic Review, Vol. 45 (2004), pp. 301-324.

MARTZKe, R. "Rush to Lock in Teams Results in Bowl Boredom." USA Today, November 20, (1990).

McKinney, C.N., Niederle, M., And Roth, A.E. "The Collapse of a Medical Labor Clearinghouse (and Why Such Failures Are Rare).” American Economic Review, Vol. 95 (2005), pp. 878-889.

NCAA. Official NCAA Football Records. August, 2003.

— AND — - "Unraveling Reduces the Scope of an Entry Level Labor Market: Gastroenterology with and without a Centralized Match.” Journal of Political Economy, Vol. 111 (2003b), pp. 1342-1352.

— AND — . "The Gastroenterology Fellowship Match: How It Failed, and Why It Could Succeed Once Again." Gastroenterology, Vol. 127 (2004), pp. 658-666.

— AND — . "The Gastroenterology Fellowship Market: Should There Be a Match?" American Economic Review, Papers and Proceedings, Vol. 95 (2005), pp. 372-375.

- AND —. "Making Markets Thick: How Norms Governing Exploding Offers Affect Market Performance." Working Paper, 2006.

—, Proctor, D.D., And Roth, A.E. "What Will Be Needed for the New GI Fellowship Match to Succeed?" Gastroenterology, Vol. 130 (2006), pp. 218-224.

Niederle, M. And Roth, A.E. "Relationship between Wages and Presence of a Match in Medical Fellowships." Journal of the American Medical Association, Vol. 290 (2003a), pp. 1153-1154.

Rотн, A.E. "The Evolution of the Labor Market for Medical Interns and Residents: A Case Study in Game Theory." Journal of Political Economy, Vol. 92 (1984), pp. 991-1016.

. "A Natural Experiment in the Organization of Entry Level Labor Markets: Regional Markets for New Physicians and Surgeons in the U.K." American Economic Review, Vol. 81 (1991), pp. 415-440.

- AND XING, X. "Jumping the Gun: Imperfections and Institutions Related to the Timing of Market Transactions." American Economic Review, Vol. 84 (1994), pp. 992-1044.

Sönmez, T. "Can Pre-Arranged Matches Be Avoided in Two-Sided Matching Markets?” Journal of Economic Theory, Vol. 86 (1999), pp. 148-156.

SoonerStats.com. “AP Poll and BCS Ranking History.” Retrieved from www.soonerstats.com/fb/polls/index.cfm January 2006.

StataCorp. “Obtaining Robust Variance Estimates.” In Stata Statistical Software: Release 7.0. College Station, Tex.: Stata Corporation. 2001.

SuEN, W. "A Competitive Theory of Equilibrium and Disequilibrium Unraveling in Two-Sided Matching." RAND Journal of Economics, Vol. 31 (2000), pp. 101-120.

2cuz.com. "Weekly AP Poll Results." Retrieved from 2cuz.com/weeks/weeks.html, July-September, 2003.

ÜNVER, M.U. "Backward Unraveling over Time: The Evolution of Strategic Behavior in the Entry-Level British Medical Labor Markets.” Journal of Economic Dynamics and Control, Vol. 25 (2001), pp. 1039-1080.

. "On the Survival of Some Unstable Two-Sided Matching Mechanisms." International Journal of Game Theory, Vol. 33 (2005), pp. 239-254.

Wooldridge, J.M. Econometric Analysis of Cross Section and Panel Data. Cambridge, Mass.: The MIT Press, 2002. 